\title{
Opsonin-independent adherence and phagocytosis of Listeria monocytogenes by murine peritoneal macrophages
}

\author{
MARCIA M. PIERCE, R. E. GIBSON and F. G. RODGERS \\ Molecular Pathogenesis and Infectious Disease Group, Department of Microbiology, Rudman Hall, University \\ of New Hampshire, Durham, NH 03824-2617, USA
}

\begin{abstract}
Listeria monocytogenes adhered to and multiplied intracellularly in murine peritoneal macrophages in the absence of opsonins. The infective process in these cells was evaluated by viable bacterial cell colony counts of intracellular organisms and documented by transmission and scanning electron microscopy. Adherence of listeriae to macrophages involved surface interactions of the prokaryotic cell surface and eukaryotic cell membranes. Subsequent phagocytosis was seen to occur through a process in which host cell-derived pseudopodia surrounded and engulfed organisms leaving them within phagosomes in the cytoplasm of infected cells. This process of uptake of $L$. monocytogenes by macrophages occurred at $4^{\circ} \mathrm{C}$. Following invasion of the cell, escape of $L$. monocytogenes from the phagosome into the cytoplasm was initiated as early as 10 min into the infective process. Intracellular multiplication of bacteria continued for $8 \mathrm{~h}$ after inoculation at which point loss of adherent macrophages due to cell lysis was evident. The mean generation time of the organism in these cells was $58 \mathrm{~min}$. The cellular and ultrastructural events of $L$. monocytogenes adherence to and phagocytosis by murine macrophages in the absence of antibody or complement have been defined.
\end{abstract}

\section{Introduction}

Listeria monocytogenes is the causal agent of listeriosis, the clinical manifestations of which range from mild influenza-like symptoms to meningoencephalitis and septic abortion. The disease primarily affects those individuals who are immunocompromised, the very young and the elderly, as well as transplant recipients and pregnant women.

L. monocytogenes is a facultative intracellular bacterial pathogen which serves as a useful model for the study of intracellular infections in general, as well as to investigate the cell-mediated immune response and the processes of inflammation in the host [1]. Establishment of intracellular infection is brought about by an initial recognition or attachment event between binding molecules or adhesins on the organism and receptors located at the host cell membrane surfaces. The process eventually leads to internalisation of the pathogen by infected cells. In experimental murine infections, Listeria organisms were shown to accumulate primarily in the liver and spleen, replicating within mononuclear phagocytic cells as well as in cells that are not professionally phagocytic including hepatocytes $[2,3]$. Intracellular growth of the organism

Received 21 Nov. 1995; accepted 26 Feb. 1996.

Corresponding author: Professor F. G. Rodgers. in host cells has been characterised in the transformed human enterocyte-like cell line Caco-2 [4] and macrophage-like J774 cells [5].

Attachment and entry of the bacteria occurs through their apical surfaces and these processes do not appear to be actin-dependent [6]. After adherence to host cells, bacteria are taken into membrane-bound phagosomes. Subsequently, the organism escapes from the phagosome and enters the cytoplasm, where the bacteria replicate [7]. Following escape from the phagocytic vacuole, the organism becomes coated with actin filaments to form a large tail or comet-like structure up to $5 \mu \mathrm{m}$ long [8]. This organism-actin complex is critical for the intercellular spread of $L$. monocytogenes in that as the actin polymerises, the pathogen is 'pushed' to the surface of the host cell and a cytoplasmic pseudopod projection is produced with the listeria at the tip. This pseudopod touches a neighbouring cell which phagocytoses it, enclosing the organism in a double-membrane vacuole [8-10]. The organism then escapes from the vacuole and repeats this cycle to initiate further infection of neighbouring cells. In this fashion, organisms remain cell-associated throughout the infective process and thereby avoid direct attack by the humoral immune system of the host [7].

Mounting a successful host defence against this 
pathogen involves a patent cell-mediated immune response with macrophage killing of internalised bacteria [1]. However, it has been shown that mononuclear phagocytes are heterogeneous with regard to listericidal activity. Murine peritoneal macrophages produced by stimulation with thioglycollate permit intracellular growth of $L$. monocytogenes, whereas macrophages stimulated by proteose-peptone are listericidal [11]. Furthermore, these workers showed that thioglycollate-stimulated macrophages utilised complement receptor 3 (CR3) as a minor binding molecule for listeriae. This suggested that an alternative host cell receptor was responsible for binding the majority of organisms to macrophages in nonlistericidal fashion. In the present study, the binding and uptake of L. monocytogenes to host cells in the absence of opsonins was investigated. Bacterial uptake in an opsonin-deficient environment may occur at the very earliest stages of disease and before the induction of antibody or increased levels of complement. Such opsonin-independent mechanisms may offer intracellular survival advantages for Listeria spp.

\section{Materials and methods}

\section{Organisms and culture conditions}

A fully virulent clinical isolate of $L$. monocytogenes serotype $1 / 2 b$ was isolated on blood agar, subcultured once on Tryptic soy agar, and stored as stock cultures frozen at $-70^{\circ} \mathrm{C}$ in serum-sorbitol $1 \%$. Virulence was assayed with fertile hens' eggs [12] and over the course of this study the LD50 for this isolate remained unchanged at $23 \mathrm{cfu}$. Thawed samples were plated on agar and incubated overnight. Colonies were harvested, resuspended in Tryptic soy broth, and cultured for $8.5 \mathrm{~h}$ to mid-exponential growth phase with shaking at $37^{\circ} \mathrm{C}$. Cells were collected by centrifugation at $5000 \mathrm{~g}$, washed with Hanks's Balanced Salts Solution (HBSS; Sigma) and resuspended in HBSS to give $1 \times 10^{9} \mathrm{cfu} /$ $\mathrm{ml}$ prior to inoculation of macrophages.

\section{Murine peritoneal macrophages}

$\mathrm{BALB} / \mathrm{c}$ mice of both sexes were used at 3-6 months of age. Murine peritoneal macrophages were elicited by intraperitoneal injection of $1.5 \mathrm{ml}$ of thioglycollate per mouse. Mice were killed by $\mathrm{CO}_{2}$ asphyxiation 2.5-3.5 days later, and peritoneal exudate cells were extracted by peritoneal cavity lavage with three $10-\mathrm{ml}$ volumes of HBSS. These cell extracts were pooled and the cells were collected by centrifugation at $220 \mathrm{~g}$ for $10 \mathrm{~min}$. Red blood cells were lysed by the addition of $9 \mathrm{ml}$ of sterile distilled water followed by $1 \mathrm{ml}$ of $10 \times$ HBSS . The cells were then washed twice with HBSS and the total number was determined by haemocytometer.

\section{Transmission electron microscopy}

Murine peritoneal macrophages at a concentration of
$1 \times 10^{7}$ cells $/ \mathrm{ml}$ and bacterial suspensions were held separately on ice for $10 \mathrm{~min}$ before mixing. Bacteria were added to suspensions of macrophages at a multiplicity of infection (MOI) of 100 bacteria/host cell in $1.5 \mathrm{ml}$ of HBSS. The inoculated cell preparations were centrifuged at $220 \mathrm{~g}$ for $10 \mathrm{~min}$ to pellet the macrophages and then at $850 \mathrm{~g}$ for $10 \mathrm{~min}$ to deposit the bacteria on to the cells [13]. During these manipulations the suspensions of bacteria and macrophages were maintained at $4^{\circ} \mathrm{C}$ with the aim of inhibiting phagocytosis. The tubes were then warmed immediately by gentle rotation in a water bath at $37^{\circ} \mathrm{C}$ to facilitate phagocytosis. Samples were collected after $1,2,3,3.5,5,10,15,20,30,40$ and 60 min intervals by centrifugation at $4^{\circ} \mathrm{C}$. For each time point, a sample was placed on ice and the supernate was removed. The harvested pellets were fixed with prewarmed glutaraldehyde $5 \% \mathrm{v} / \mathrm{v}$ in $0.05 \mathrm{M}$ cacodylate buffer containing $10 \mathrm{mM} \mathrm{MgSO}_{4}$ at $\mathrm{pH} 7.2$ (CB). A 0 min sample was collected immediately after the initial centrifugation steps and this was fixed in glutaraldehyde in $\mathrm{CB}$ pre-cooled to $4^{\circ} \mathrm{C}$.

Samples were washed 10 times with $\mathrm{CB}$, and preembedded in Noble agar $2 \% \mathrm{w} / \mathrm{v}$ at $55^{\circ} \mathrm{C}$. Cells in agar were cut into $1-\mathrm{mm}^{3}$ blocks and post-fixed in $\mathrm{OsO}_{4} 1 \% \mathrm{w} / \mathrm{v}$ in $\mathrm{CB}$ for $36 \mathrm{~h}$. Samples were then dehydrated in an ethanol series to propylene oxide and embedded in an epon-araldite resin mixture. After polymerisation at $60^{\circ} \mathrm{C}$ for $24 \mathrm{~h}$, blocks were trimmed and sectioned on an LKB ultramicrotome III. Sections of c. $60 \mathrm{~nm}$ thickness were stained for $1 \mathrm{~min}$ each with uranyl acetate $5 \% \mathrm{w} / \mathrm{v}$ and lead citrate $0.4 \% \mathrm{w} / \mathrm{v}$, and examined at $75 \mathrm{kV}$ in the transmission mode of a H-600 scanning-transmission electron microscope.

\section{Scanning electron microscopy}

For scanning electron microscopy (SEM), macrophages were harvested as described above. Three $\mathrm{ml}$ of RPMI1640 medium, which contained $1 \times 10^{6}$ cells in fetal bovine serum (FBS) 10\% were seeded into wells of sixwell culture plates (Costar, Cambridge, MA, USA), each of which contained a sterile $22-\mathrm{mm}$ diameter glass coverslip. The cells were incubated at $37^{\circ} \mathrm{C}$ for $3 \mathrm{~h}$. The cultures were washed three times with HBSS to remove unbound cells and cell culture medium. Two $\mathrm{ml}$ of HBSS were placed on the cells and L. monocytogenes was added in HBSS at a MOI of 100 bacteria/host cell $\left(1 \times 10^{8} \mathrm{cfu} /\right.$ well $)$. The plates were then incubated at $37^{\circ} \mathrm{C}$ in the presence of $\mathrm{CO}_{2} 5 \%$ and samples were taken at prescribed times points for $1 \mathrm{~h}$. Non-adherent bacteria were removed by washing the cell cultures three times with HBSS and the cells were fixed in glutaraldehyde $5 \% \mathrm{v} / \mathrm{v}$ in $\mathrm{CB}$ for $24 \mathrm{~h}$. Samples were then washed 10 times with $\mathrm{CB}$ in situ, and dehydrated with a graded ethanol series followed by drying from hexamethyldisalizane (Electron Microscopy Sciences, Fort Washington, PA, USA). Monolayers were then sputter coated with $20 \mathrm{~nm}$ of gold-palladium in a 
Hummer $\mathrm{V}$ sputter coater and observed in an AMR 1000 scanning electron microscope at $60 \mathrm{kV}$.

\section{Intracellular growth studies}

To define the binding, uptake and intracellular replication of $L$. monocytogenes in peritoneal macrophages further, viable bacterial colony counts (VBCC) were used. Macrophages were placed in six-well plates at $1 \times 10^{6}$ cells/well and allowed to adhere for $8 \mathrm{~h}$. Cultures were washed three times with HBSS to remove non-adherent cells and serum. L. monocytogenes cells were suspended in HBSS and added to the wells at a MOI of 1 . Bacteria were allowed to adhere to and penetrate macrophages for $1 \mathrm{~h}$ at $37^{\circ} \mathrm{C}$. The cells were washed three times to remove non-adherent bacteria and RPMI-1640 with FBS 10\% and gentamicin $6 \mu \mathrm{g} / \mathrm{ml}$ was added to the cell monolayers. After washing to remove antibiotic, samples were collected each hour for $9 \mathrm{~h}$ (Fig. 1) by which time an appreciable loss of adherent macrophages was noted. Adherent cells were lysed in $2 \mathrm{ml}$ of sterile water and disrupted by agitation with a Pasteur pipette. For each time period, a $100-\mu 1$ sample was removed from the lysate samples and serially diluted in peptone $1 \%$ and plated in duplicate on Tryptic soy agar for enumeration of intracellular listeriae. Results were expressed as $\mathrm{cfu} / \mathrm{ml}$ of macrophage lysate.

\section{Results and discussion}

Successful adherence to and infection of murine peritoneal macrophages by $L$. monocytogenes occurred

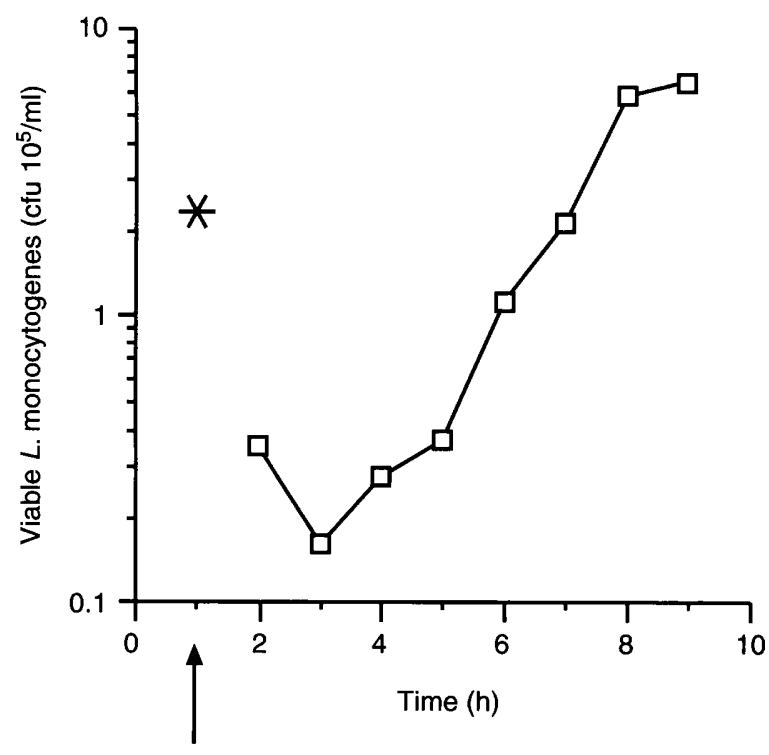

Fig. 1. Intracellular growth of $L$. monocytogenes in murine peritoneal macrophages; c. $14 \%$ of the bacterial inoculum adhered to macrophages. Mean generation time between 3 and $8 \mathrm{~h}$ was $58 \mathrm{~min}$. Arrow indicates time at which gentamicin was added. *Number of organisms attached to macrophages at time of addition of gentamicin. Cell lysis was evident by $8 \mathrm{~h}$ of intracellular growth. in the absence of the opsonic components, complement or antibody. SEM observations of monolayers showed numerous listeriae adherent to filopodia extending from macrophages (Fig. 2A) as well as organisms bound directly to the surface membranes of these cells (Fig. 2B). In both cases there were few host cell changes. Extracellular bacteria apparently bound to the macrophages in all stages of infection involved single bacteria or organisms in the process of binary fission. Observation of TEM thin-sections showed electrondiffuse cytoplasmic material streaming from apparent lytic points in the host cell surface membrane in apposition to organisms (Fig. 2C and inset). This phenomenon was undoubtedly due to the localised action of listeriolysin $\mathrm{O}$ produced by individual organisms. Indeed, the presence of $\geqslant 10$ listeriae bound to individual macrophages frequently induced cell lysis in the absence of infection. This destruction detected by electron microscopy was confirmed during growth studies of macrophages infected with $L$. monocytogenes at a MOI of 100 . Under conditions of high inocula, host cells were lost rapidly due to lysis and by $4 \mathrm{~h}$ after inoculation, $>90 \%$ of the macrophages were nonadherent. Heavily infected Caco- 2 cells have also been reported to lyse over a similar period [14].

Examination of peritoneal macrophages by TEM showed listeriae within cells in all samples, including those cells taken immediately after centrifugation. Large numbers of the cell-associated listeriae were located within the cytoplasm of macrophages despite being maintained on ice, which indicated that uptake of the organism in the absence of opsonins occurred at low temperatures. Similar findings have been reported for an opsonin-mediated system [15]. At the earliest stages of infection of macrophages, all intracellular bacteria were present in membrane-bound phagosomes. The first bacteria seen partially free in the cytoplasm of peritoneal macrophages occurred in samples collected $10 \mathrm{~min}$ after infection (Fig. 2D). This phenomenon was detected earlier in these primary macrophages than was reported for the transformed macrophage-like cell line, J774, in which free listeriae were seen in the cytoplasm $30 \mathrm{~min}$ after inoculation [8]. L. monocytogenes was taken up by the usual mechanisms of phagocytosis (Fig. 2E) in the absence of coiling phagosomes [13]. This may be due to the absence of opsonic components in this system. Indeed, coiling phagosomes were not observed during initial infection of U-937 cells with L. pneumophila in the absence of opsonins [16]. The molecular events that mediate uptake may vary in the absence or presence of opsonins; however, these differences remain to be established. As early as $1 \mathrm{~min}$ after inoculation, numerous intracellular bacteria were seen within phagosomes by TEM (Fig. 2F).

It has been postulated that the receptor by which intracellular pathogens are recognised by macrophages may define their intracellular fate [17]. In a study 

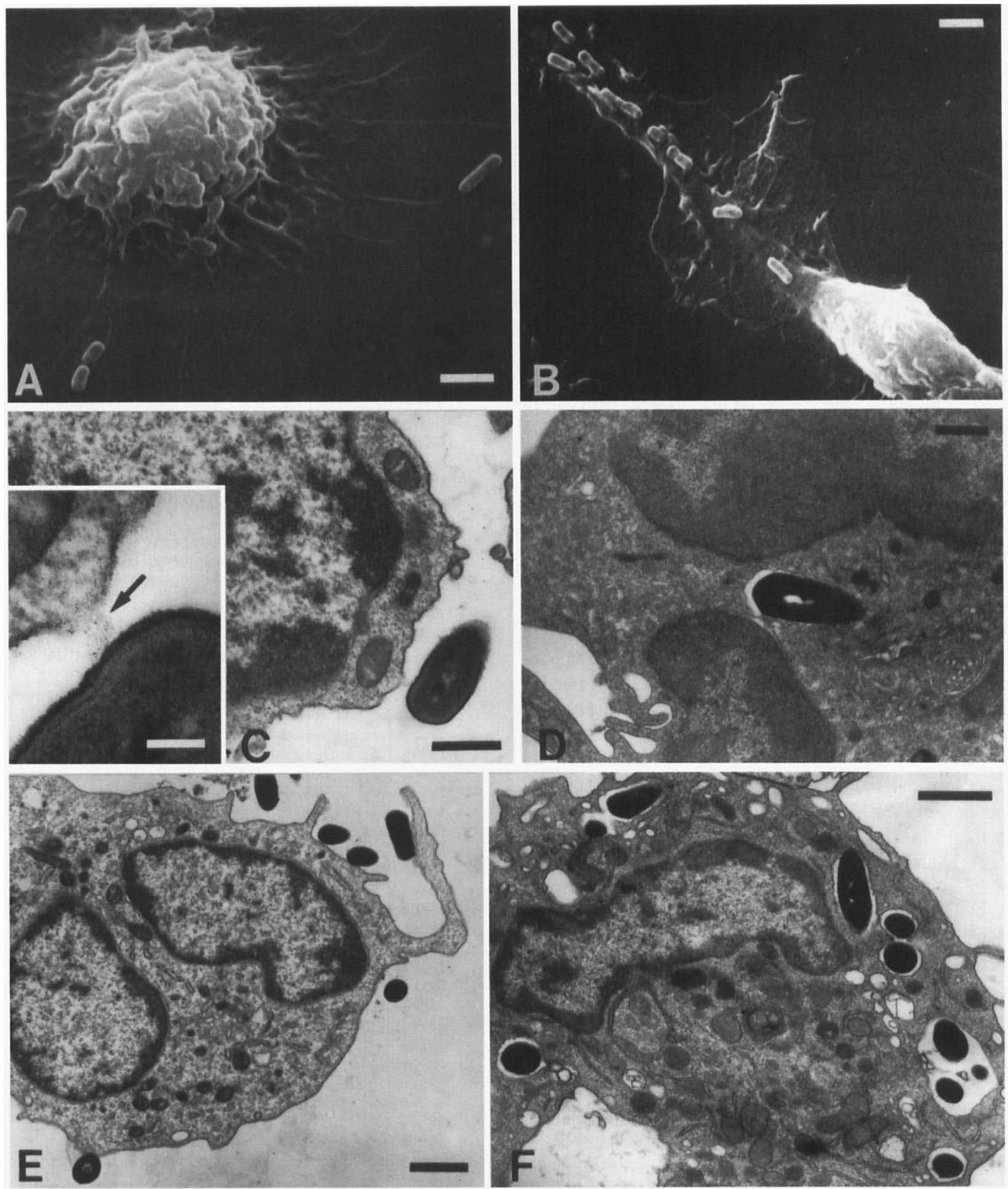

Fig. 2. Ultrastructure of the adherence and opsonin-independent uptake of L. monocytogenes by murine peritoneal macrophages. A, Scanning electron micrograph of a macrophage with multiple organisms shown bound to host cell filopodia; $\times 4500$; bar $=2 \mu \mathrm{m}$. B, Scanning electron micrograph of a macrophage with numerous listeriae bound directly to the cytoplasmic membrane; $\times 3600 ; \mathrm{bar}=2 \mu \mathrm{m}$. C, Transmission electron micrograph of a macrophage with a single bacterium undergoing wash-resistant attachment at 5 min after inoculation; $\times 22950$; bar $=0.5 \mu \mathrm{m}$. Inset: Close association of organism surface with host cell plasma membrane is evident. Note macrophage cytoplasmic material between organism and macrophage membrane (arrow) released due to the localised action of listeriolysin $\mathrm{O}$; $\times 93600 ;$ bar $=0.1 \mu \mathrm{m}$. D, Internalised organism showing partial escape of the bacterium from the phagosome occurring at $10 \mathrm{~min}$ after infection; $\times 17550 ; \mathrm{bar}=0.5 \mu \mathrm{m}$. E, Transmission electron micrograph of organisms undergoing phagocytosis $3 \mathrm{~min}$ after inoculation. Note pseudopodia engulfing organisms; $\times 9360 ; \mathrm{bar}=1 \mu \mathrm{m}$. F, Transmission electron micrograph of macrophage showing many internalised listeriae at 1 min after inoculation; $\times 11700 ;$ bar $=1 \mu \mathrm{m}$. 
outlining the uptake of Mycobacterium tuberculosis it was shown that when bacterial entry was mediated by Fc receptors, lysosome-associated phagocytic vesicles resulted, whereas entry via CR3 receptors induced the formation of lysosome-free vesicles [17]. It is possible that such differences exist in the intracellular fate of $L$. monocytogenes taken up by opsonin-dependent and opsonin-independent mechanisms.

VBCC count data showed that c. $2.3 \times 10^{5}$ listeria attached to $1 \times 10^{6}$ macrophages by $1 \mathrm{~h}$ after inoculation, indicating that c. $14 \%$ of the bacterial inoculum had bound to the cell monolayers. Growth curves of $L$. monocytogenes demonstrated that the organism did not replicate in unsupplemented HBSS. The minimum inhibitory concentration (MIC) of gentamicin in RPMI-1640 with FBS 10\% was determined as $0.6 \mu \mathrm{g} / \mathrm{ml}$ for this strain. By $2 \mathrm{~h}$ after the addition of gentamicin at 10 -fold the MIC, the number of cfu measured declined to $7 \%$ of the originally adherent bacteria, indicating death of extracellular listeriae. The mean generation time (Fig. 1) in these macrophages was shown to be $c$. $58 \mathrm{~min}$, compared to $90 \mathrm{~min}$ reported for Caco- 2 cells [14] and 40 min seen in bone-marrow-derived murine macrophages [7]. At $9 \mathrm{~h}$ after inoculation, the monolayers were significantly disrupted by the infective process and $>95 \%$ of the macrophages were detached or lysed.

This work demonstrated the effective adherence and uptake of $L$. monocytogenes by murine peritoneal macrophages in an opsonin-independent fashion. It has been shown that thioglycollate-elicited, non-listericidal macrophages take up Listeria cells through CR3 only $33 \%$ of the time [15]. In addition, non-listericidal macrophages phagocytosed listeria more efficiently than did proteose-peptone-elicited, listericidal macrophages. In contrast, CR3 mediated c. $66 \%$ of the uptake of serum-opsonised listeria by listericidal macrophages and of these phagocytosed organisms only $2 \%$ were successful in escaping from the phagosome into the cytoplasm as compared to bacteria phagocytosed by non-listericidal macrophages. Furthermore, these organisms showed an increase in the number of actin-coated bacteria compared with the number of bacteria phagocytosed. Successful binding of this pathogen to macrophages facilitates replication and enhances infection of the host. Therefore, it seems certain, that these opsonin-independent binding processes play an important role in the successful infection of permissive host macrophages by $L$. monocytogenes, especially in the very early stages of listeriosis.
We thank D. Slater and K. Richard for technical assistance, and Dr F. C. Gibson and S. Maganti for helpful comments. This work was supported by a Hatch grant from the US Department of Agriculture \# $\mathrm{NH} 00333$ and by a Central University Research Fund grant from the Office of Sponsored Research, University of New Hampshire.

\section{References}

1. Kaufmann SHE. Immunity to intracellular bacteria. Annu Rev Immunol 1993; 11: 129-163.

2. Mackaness GB. Cellular resistance to infection. J Exp Med 1962; 116: 381-406

3. Conlan JW, Dunn PL, North RJ. Leukocyte-mediated lysis of infected hepatocytes during listeriosis occurs in mice depleted of NK cells or CD4+CD8+Thy1.2+T cells. Infect Immun 1993; 61: 2703-2707.

4. Mounier J, Ryter A, Coquis-Rondon M, Sansonetti PJ. Intracellular and cell-to-cell spread of Listeria monocytogenes involves interaction with $\mathrm{F}$-actin in the enterocytelike cell line Caco-2. Infect Immun 1990; 58: 1048-1058.

5. Portnoy DA, Chakraborty T, Goebel W, Cossart P. Molecular determinants of Listeria monocytogenes pathogenesis. Infect Immun 1992; 60: 1263-1267.

6. Karunasagar I, Senghaas B, Krohne G, Goebel W. Ultrastructural study of Listeria monocytogenes entry into cultured human colonic epithelial cells. Infect Immun 1994; 62: 3554 3558.

7. De Chastellier C, Berche P. Fate of Listeria monocytogenes in murine macrophages: evidence for simultaneous killing and survival of intracellular bacteria. Infect Immun 1994; 62: 543553.

8. Tilney LG, Portnoy DA. Actin filaments and the growth, movement, and spread of the intracellular bacterial parasite, Listeria monocytogenes. J Cell Biol 1989; 109: 1597-1608.

9. Dabiri GA, Sanger JM, Portnoy DA, Southwick FS. Listeria monocytogenes moves rapidly through the host-cell cytoplasm by inducing directional actin assembly. Proc Natl Acad Sci USA 1990; 87: 6068-6072.

10. Cossart P, Kocks C. The actin-based motility of the facultative intracellular pathogen Listeria monocytogenes. Mol Microbiol 1994; $13: 395-402$

11. Drevets DA, Canono BP, Campbell PA. Listericidal and nonlistericidal mouse macrophages differ in complement receptor type 3-mediated phagocytosis of $L$. monocytogenes and in preventing escape of the bacteria into the cytoplasm. $J$ Leukoc Biol 1992; 52: 70-79.

12. Basher HA, Fowler DR, Rodgers FG, Seaman A, Woodbine M. Pathogenesis and growth of Listeria monocytogenes in fertile hens' eggs. Zentralbl Backteriol Mikrobiol Hyg A 1984; 256: 497-509.

13. Horwitz MA. Phagocytosis of the Legionnaires' disease bacterium (Legionella pneumophila) occurs by a novel mechanism: engulfment within a pseudopod coil. Cell 1984; 36: 27-33.

14. Gaillard J-L, Berche P, Mounier J, Richard S, Sansonetti P. In vitro model of penetration and intracellular growth of Listeria monocytogenes in the human enterocyte-like cell line Caco-2. Infect Immun 1987; 55: 2822-2829.

15. Drevets DA, Campbell PA. Macrophage phagocytosis: use of fluorescence microscopy to distinguish between extracellular and intracellular bacteria. J Immunol Methods 1991; 142: 3138.

16. Rodgers FG, Gibson FC. Opsonin-independent adherence and intracellular development of Legionella pneumophila within U937 cells. Can J Microbiol 1993; 39: 718-722.

17. Small PLC, Ramakrishnan L, Falkow S. Remodeling schemes of intracellular pathogens. Science 1994; 263: 637-639. 